\title{
Short-Term (0-48 h) Effects of Maternal Betamethasone Administration on Fetal Heart Rate and Its Variability
}

\author{
M. SIMONE LUNSHOF, KEES BOER, HANS WOLF, SANDER KOPPEN, \\ JEANETTE KLIJN VELDERMAN, AND EDUARD J.H. MULDER \\ Department of Obstetrics and Gynecology [M.S.L., K.B., H.W., S.K., J.K.V.], Academic Medical Center, \\ University of Amsterdam, 1100 DE, Amsterdam, The Netherlands, Department of Perinatology and \\ Gynecology [E.J.H.M.], Wilhelmina Children's Hospital, University Medical Center Utrecht, 3584 EA, \\ Utrecht, The Netherlands
}

\begin{abstract}
ABSTR
The short-term $(0-48 \mathrm{~h})$ effects of maternal betamethasone
administration on computerized fetal heart rate (FHR) parame-
ters were studied in 36 pregnancies at increased risk for preterm
delivery. FHR was recorded for 90 min immediately before the
start of betamethasone treatment and again at 6-h intervals during
the next 48 h. Multiple linear regression models were used to
assess the possible effects on FHR parameters of gestational age,
time of day, clinical indication for treatment, and use of tocolytic
drugs. Within 12 h after the start of treatment, significant in-
creases occurred in FHR accelerations, and short- and long-term
FHR variability (36\%, $28 \%$, and $22 \%$, respectively), whereas
basal FHR showed a $5 \%$ decrease. FHR variability was de-
creased by $10 \%$ at $42-48 \mathrm{~h}$. The observed changes were more
pronounced in older (29-33 wk of gestation) compared with
\end{abstract}
\section{ABSTRACT}

younger fetuses (25-28 wk of gestation). Decelerations occurred only in 4 out of 11 compromised fetuses during betamethasone therapy. We conclude that there are significant changes in FHR parameters during the first $48 \mathrm{~h}$ after betamethasone administration. These changes are transient in normal fetuses. However, the compromised fetus may be adversely affected by betamethasone.

(Pediatr Res 57: 545-549, 2005)
ACC, number of fetal heart rate accelerations
FHR, fetal heart rate
LTV, long-term variability
STV, short-term variability

Antenatal corticosteroid administration to pregnant women with threatened preterm delivery has proven to successfully reduce the risk of sequelae of prematurity, such as the respiratory distress syndrome $(1,2)$. Recent findings in the fetus and neonate have focused attention on a variety of extrapulmonary effects of corticosteroids, including side effects on metabolic, endocrine, immunologic, cardiovascular, and CNS function (3-10). Maternal betamethasone administration has been described to transiently reduce fetal movements and heart rate variability, which are commonly used as indicators of the fetal condition (5-10). The reductions were most profound $48-72 \mathrm{~h}$ after the first of two injections of betamethasone (doses $24 \mathrm{~h}$ apart) in studies that comprised 1-h recordings made on each of five successive days.

Betamethasone readily crosses the placenta and fetal levels keep pace with the rapidly increasing maternal levels during

Received July 28, 2003; accepted August 5, 2004.

Correspondence: M.S. Lunshof, M.D., Ph.D., Onze Lieve Vrouwe Gasthuis, Department of Obstetrics and Gynecology, P.O. Box 95500, 1090 HM Amsterdam, The Netherlands; e-mail: S.Lunshof@AMC.UvA.NL

DOI: 10.1203/01.PDR.0000155948.83570.EB the first few hours after administration of this drug (11). It may, therefore, be anticipated that betamethasone already exerts an effect on the fetus shortly after injection to the mother. However, the few studies that have reported on early effects of betamethasone showed an increase in FHR variability, an increase or decrease in basal FHR, or no change at all in either parameter when data were obtained within $24 \mathrm{~h}$ postinjection $(5,6,8,10)$.

The present study was designed to study the temporal effect of maternal betamethasone administration on various FHR parameters at 6-h intervals during the first $48 \mathrm{~h}$ after the initiation of treatment. We took into account the possible influences of the time of day at which betamethasone was administered, time of day at which FHR recording occurred, gestational age, the clinical indication for steroid treatment, and the use of tocolytic drugs.

\section{METHODS}

Subjects. This study was approved by the local ethical committee. Thirtysix pregnant women at $25^{+0}$ to $32^{+4}$ (mean, $29^{+3}$ ) weeks of gestation (wGA) and at high risk for preterm delivery participated after informed written 
consent was obtained. Six patients who received a repeat course of betamethasone (10-d interval) participated twice in the study. There was one twin pregnancy and the two fetuses were recorded simultaneously. A total of 43 sets of records were obtained. Clinical information and outcome of pregnancy are presented in Table 1. All infants did well in the neonatal period, except for one case with respiratory distress syndrome (Table 2). Five study groups were distinguished. Women with threatened preterm labor were treated with either ritodrine (group 1, $n=6$ ) or nifedipine (group 2, $n=5$ ). The use of these tocolytic drugs was randomized as part of a study designed to compare their tocolytic and maternal and fetal effects. Group 3 comprised pregnancies complicated by preeclampsia $(n=1)$, intrauterine growth restriction (IUGR, $n$ $=1)$, or both $(n=9)$. Preeclampsia was defined as the presence of both diastolic blood pressure $>90 \mathrm{~mm} \mathrm{Hg}$ and proteinuria $>0.3 \mathrm{~g} / \mathrm{L}$ (12). Six out of the 10 preeclamptic patients were treated with methyldopa, an antihypertensive drug with no reported effects on fetal hemodynamics (13). IUGR fetuses were defined as having an ultrasonographically estimated weight $<5$ th percentile on a reference chart (14). Doppler blood flow velocity waveforms of the umbilical artery were abnormal in all pregnancies in this group (pulsatility index $>95$ th percentile for gestation) (15), except for one pregnancy complicated by preeclampsia only. During the 48 -h study period, four preeclamptic patients underwent cesarean section because of suspected fetal distress (Table 2). As they did not complete the whole study period, their results were excluded, leaving a total of 39 sets of records for statistical analysis (main group, Table 1). Women with preterm rupture of the membranes (PROM) without uterine contractions formed group 4. Group 5 comprised pregnant women treated with betamethasone for miscellaneous reasons, e.g. vaginal bleeding, placenta previa, or cervical cerclage. The patients in groups 4 and 5 did not receive any other medication than betamethasone.

Betamethasone treatment. Betamethasone (Celestone Chronodose, Schering-Plough, Berlin, Germany; $24 \mathrm{mg}$ ) was administered intramuscularly in two doses $24 \mathrm{~h}$ apart. Because clinical practice did not allow for standardization of betamethasone administration, the timing of the first dose varied widely among the patients. This occurred between 0800 and $2000 \mathrm{~h}$ in $95 \%$ of the cases and on average between 1300 and $1400 \mathrm{~h}$.

Fetal heart rate recordings. Fetal heart rate was monitored with a cardiotocograph (Oxford, Sonicaid Ltd., Chichester, UK) and analyzed off-line by the System 8002 FHR analysis program (16). Basal FHR (bpm), short-term (STV, $\mathrm{ms}$ ) and long-term variation (LTV, ms), and the numbers per hour of accelerations $(\mathrm{ACC},>15 \mathrm{bpm}$ and $>15 \mathrm{~s})$ and decelerations $(>15 \mathrm{bpm}$ and $>15 \mathrm{~s})$ were calculated by this program for each recording. Seven recordings lasting 90 min each were obtained from each individual during the study period. One recording was made immediately before the administration of the first dose of betamethasone (reference recording). All reference recordings met the DawesRedman criteria, i.e. they showed normal FHR and variability, and decelerations were absent (16). Subsequently, six other recordings were made at intervals of approximately $6 \mathrm{~h}$ during the next $48 \mathrm{~h}$, except during the night (2400-0700 h).

Statistical analysis. Statistical analysis was carried out in three main steps. First, using linear regression analysis, we tested whether the FHR parameters of the reference recordings were influenced by the time of day at which they had been made. Three groups of recordings made at 0700-1200 h $(n=17)$, $1200-1800 \mathrm{~h}(n=18)$, and $1800-2400 \mathrm{~h}(n=8)$, were compared using two dummy variables.

Second, a multiple linear regression model with dummy variables was used to determine whether FHR parameters changed significantly from their pretreatment levels after betamethasone administration. Dependent variables were the FHR parameters during each 6-h episode, expressed as the absolute change from their pretreatment level. Independent variables were a series of eight dummy variables, indicating the time lapse between the first dose of betamethasone and the start of recording. The first dummy was given the value 1 if the recording was made during the first 6-h episode after administration, and the value 0 if not. The second dummy was given the value 1 if the recording fell in the second 6-h episode, and 0 if otherwise. Dummies 3 through 8 were defined similarly. To avoid biased significance levels, multiple observations on the same individual were taken into account by including a separate dummy variable for each individual. The estimated regression coefficients gave the average change in FHR parameter for each of the eight successive 6-h episodes. To determine whether a particular coefficient was significantly different from zero, indicating a significant rise or fall in the FHR parameter in that episode, $t$ test was used. Note that by using dummies rather than time series analysis, we avoided imposing a monotonously increasing or decreasing trend.

Third, to test whether the outcome measures of step 2 were affected by the time of day at which FHR recording had taken place, we re-estimated the equations of step 2 by following the step 1 procedure. Only for those intervals for which step 2 revealed a significant change in any of the FHR parameters, additional regression procedures were carried out to study the effects of the clinical indication for treatment and gestational age at recording (pregnancies at 25-28 wGA versus those at 29-33 wGA). The effects of these variables were evaluated with the $t$ test using $p<0.05$ as the level of significance.

\section{RESULTS}

There was no significant relationship between the time of day at which the reference recordings were made and the values of any of the FHR parameters (step 1 of analysis). For all sets of records combined $(n=39)$, the effects on each FHR parameter of the first and second doses of betamethasone are shown in Figure 1, $a-d$. Step 2 of analysis showed a significant decrease in basal FHR 6-12 h after the first dose, whereas FHR variation (both LTV and STV) and ACC increased gradually during the first $12 \mathrm{~h}$, reaching a maximal change from pretreatment levels $6-12 \mathrm{~h}$ after injection. The mean changes were $-5 \%, 22 \%, 28 \%$, and $36 \%$, for FHR, LTV, STV, and ACC, respectively ( $p<0.01$ for all). Basal FHR and its variation

Table 1. Clinical data and outcome of pregnancy in five distinct groups of patients treated with betamethasone to enhance fetal lung maturation

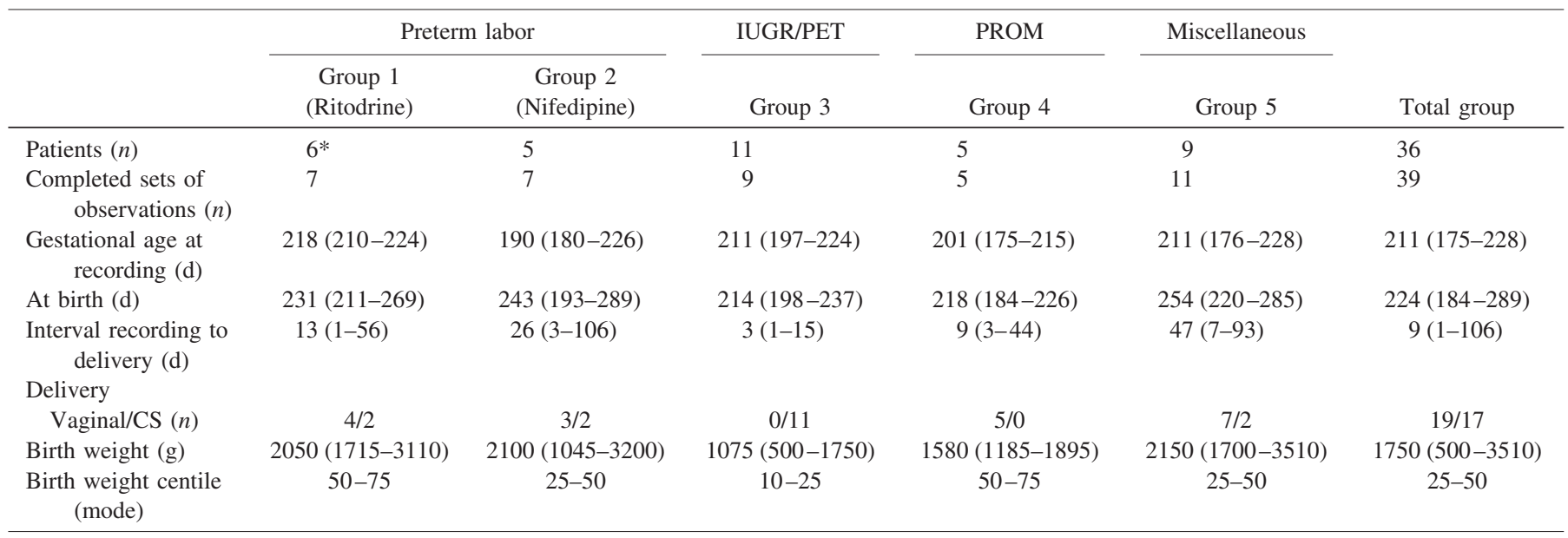

Data are presented as median (range) or number $(n)$.

IUGR, intrauterine growth restriction; PET, preeclampsia; PROM, preterm rupture of membranes; CS, cesarean section.

* Including one twin pair. 
Table 2. Clinical data and pregnancy outcome of four preeclamptic patients who underwent cesarean section (CS) within the study period because of suspected fetal distress based on abnormalities of the FHR pattern

\begin{tabular}{ccccccccc}
\hline $\begin{array}{c}\text { Case } \\
\text { no. }\end{array}$ & IUGR & $\begin{array}{c}\text { Doppler } \\
\text { abnormality }\end{array}$ & \multicolumn{1}{c}{ Indication for CS } & $\begin{array}{c}\text { Interval } \\
\text { beta-CS }\end{array}$ & $\begin{array}{c}\text { GA at } \\
\text { birth }(\text { wk })\end{array}$ & $\begin{array}{c}\text { Birth } \\
\text { weight }(\mathrm{g})\end{array}$ & $\begin{array}{c}\text { pH } \\
\text { Remark }\end{array}$ \\
\hline 1 & + & + & Prolonged bradycardia & $22 \mathrm{~h}$ & $30^{+4}$ & 1040 & 7.19 \\
2 & + & + & Prolonged bradycardia & $23 \mathrm{~h}$ & $30^{+4}$ & 1075 & 7.13 \\
3 & + & + & Flat FHR pattern; repetitive decelerations & $27 \mathrm{~h}$ & $28^{+2}$ & 855 & 7.07 & - \\
4 & - & - & Flat FHR pattern; repetitive decelerations & $41 \mathrm{~h}$ & $32^{+2}$ & 1750 & $7.24^{*}$ & - \\
\hline
\end{tabular}

IUGR, intrauterine growth restriction; Doppler abnormality, increased pulsatility index of the umbilical artery; $+/-$, presence or absence; interval beta-CS, interval (h) between the first dose of betamethasone and $\mathrm{CS} ; \mathrm{pH}, \mathrm{pH}$ of the umbilical vein at birth; IRDS, idiopathic respiratory distress syndrome.

* Arterial $\mathrm{pH}$ of the baby within $1 \mathrm{~h}$ after birth.
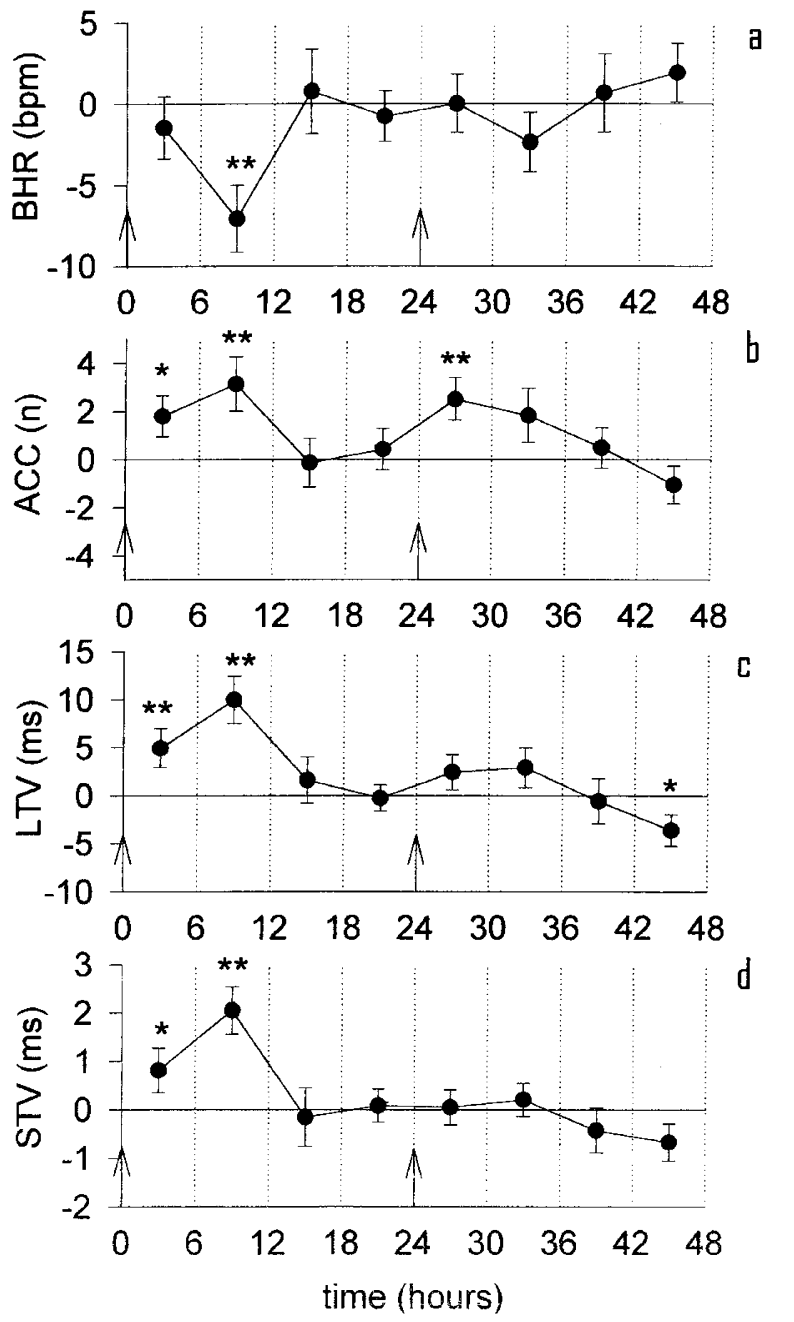

Figure 1. Mean changes ( \pm SEM) from baseline levels of $(a)$ basal fetal heart rate (BHR), (b) the number of accelerations (ACC), $(c)$ LTV, and $(d)$ STV during the first $48 \mathrm{~h}$ after the start of betamethasone treatment in the main study group $(n$ $=39$ sets of observations). The arrows indicate the time of administration of the first and second dose of betamethasone. ${ }^{*} p<0.05$; ${ }^{* *} p<0.01$.

were negatively correlated both before treatment $(R=-0.54$ and $R=-0.48$ for LTV and STV, respectively) and $6-12 \mathrm{~h}$ after the first dose of betamethasone $(R=-0.57$ and $R=$ -0.55 , respectively; $p<0.01$ for all four relationships). After the second dose, there were no significant changes in FHR, LTV, or STV, but ACC increased again $0-6 \mathrm{~h}$ after injection (28\% from pretreatment level; $p<0.01$; Fig. $1 b$ ). At the end of the 48-h study period, LTV and STV were both reduced by $10 \%$ as compared with control values, but only for LTV the

change was statistically significant $(p<0.05$; Fig. $1 c)$. Decelerations hardly occurred among the recordings of the main group and were not further analyzed.

After inclusion of the time of day at which the serial recordings had been made (step 3 of analysis), most t-values were slightly reduced. However, the described changes in FHR, ACC, LTV, and STV, and also their levels of significance remained unaffected.

The changes in FHR parameters seen in the main group occurred similarly in each of the distinct clinical groups and did not differ significantly between these groups. Gestational age at the time of drug administration appeared to be an important variable. All changes in FHR parameters that occurred $0-12 \mathrm{~h}$ after the first dose of betamethasone were significant in the fetuses studied between $29^{+0}$ and $32^{+4}$ wGA $(n=24)$, but not in the younger fetuses $\left(25^{+0}\right.$ to $28^{+6}$ wGA, $\left.n=15\right)$. Also, the increase in ACC seen $0-6 \mathrm{~h}$ after the second dose of betamethasone was only significant in the fetuses treated after $29^{+0}$ wGA $(p<0.01)$.

Four preeclamptic patients underwent cesarean section within the study period, as clinical signs of fetal distress emerged after betamethasone administration (Table 2). These included pathologic decelerations or a flat FHR tracing with repetitive decelerations. Impaired fetoplacental blood flow (raised umbilical artery Pulsatility Index values but no absent end-diastolic flow) had been demonstrated before the start of treatment in three of four fetuses (Table 2). Computerized FHR analysis (results not known to the physicians) demonstrated no major change with time in basal FHR (Fig. 2a), but there were
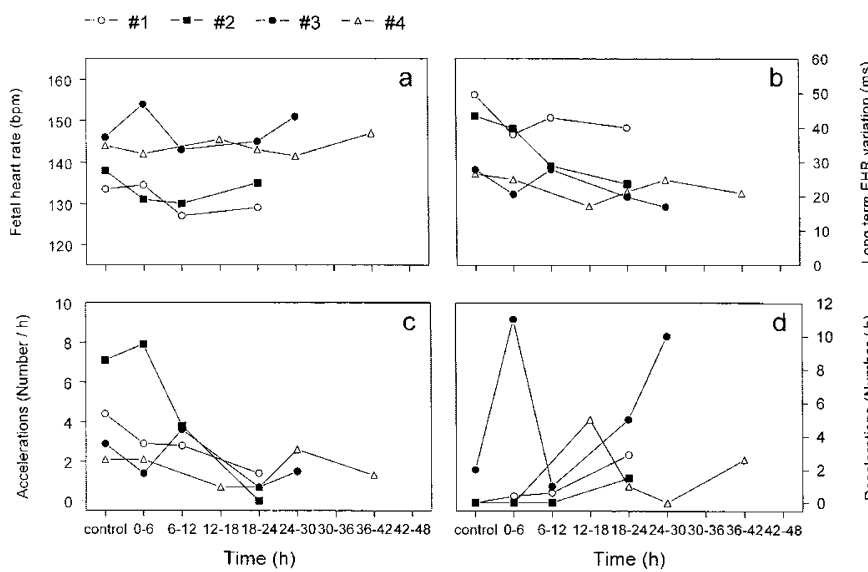

Figure 2. Course of basal FHR (a), long-term FHR variation (b), and the numbers per hour of FHR accelerations $(c)$ and decelerations $(d)$ in four fetuses of preeclamptic patients who were delivered during the 48 -h study period because of emerging clinical signs of fetal distress. 
decreases in LTV (Fig. 2b), STV (data not shown), and ACC (Fig. 2c). The number of pathologic decelerations on the other hand increased considerably over time (Fig. 2d). Three fetuses appeared to be acidotic at birth (Table 2). Determination of the umbilical cord $\mathrm{pH}$ failed in one case, but the arterial $\mathrm{pH}$ value obtained within $1 \mathrm{~h}$ after birth (7.24) made it unlikely that this fetus had been acidotic at birth (Table 2).

Comment. The present study aimed to determine the acute effects on FHR parameters of two doses of betamethasone maternally administered $24 \mathrm{~h}$ apart. The study was confined to the first $48 \mathrm{~h}$ of therapy, but, as three 90 -min recordings were made per day, the corticosteroid effects were investigated much more frequently and extensively than in previous studies. In these studies, FHR monitoring had been performed for 10-60 min on each of five successive days, but evaluation of the betamethasone effects did usually not start until $24 \mathrm{~h}$ after the first dose had been given (5-9). Therefore, the present study was designed to provide essential information about the early cardiovascular effects of betamethasone. Such data are not only important for obstetric management in case of threatened preterm delivery, but also for clinical surveillance of the neonate when treated with corticosteroids (3).

In the main study group, we found primary effects, i.e. a decrease in basal FHR and increases in FHR variability and ACC $0-12 \mathrm{~h}$ after the first betamethasone dose, with the largest effects $6-12 \mathrm{~h}$ postinjection. Secondary effects appearing after the second dose of betamethasone showed that ACC were increased again $(0-6 \mathrm{~h})$ and that FHR variability was decreased $(18-24 \mathrm{~h})$, whereas basal FHR remained unchanged during this 24-h period. These effects were most pronounced in the older fetuses studied between 29 and $33 \mathrm{wGA}$, but not related to the time of day at which betamethasone was administered, time of day at which FHR monitoring occurred, the clinical indication for treatment, or the use of tocolytic or antihypertensive drugs.

Our study differed principally from all previous studies by its frequent FHR sampling throughout the first $48 \mathrm{~h}$ of therapy. In only one study (10), first FHR assessment occurred $8 \mathrm{~h}$ postinjection (median; range, 2-15 h). Despite this wide range in time, the primary effects of corticosteroids described by Subtil et al. (10) are the only existing data to date with which to compare our results. The authors found similar (biphasic) time courses of FHR parameters after the administration of short-acting betamethasone, long-acting betamethasone, and dexamethasone, when analyzed statistically for the entire 5-d study period. In detail, however, there were differential effects among the three formulations, as FHR was increased for long-acting betamethasone at $8 \mathrm{~h}$ into the study, whereas FHR was decreased at that time for short-acting betamethasone and dexamethasone. Our results on long-acting betamethasone are therefore in line with the effects of short-acting betamethasone and dexamethasone seen in the study by Subtil $e t$ al. (10), but opposite to their result for long-lasting betamethasone. Although this discrepancy in result at $6-12 \mathrm{~h}$ postinjection may be merely a matter of chance, methodological differences between the two studies might have played a role. The latter include differences in the time at first FHR monitoring after initiation of corticosteroid therapy, differences in FHR monitoring [once daily with records of variable and relatively short duration in the study by Subtil et al. versus three recordings per day of fixed length (90 $\mathrm{min})$ in the present study], and a difference in mean gestational age at recording (32 wGA versus 29 wGA, respectively).

A FHR-decreasing effect of synthetic corticosteroids has also been found in studies on preterm human infants $(17,18)$ and the fetal sheep and baboon (19-21). The decrease in FHR generally occurred within one to several hours after the start of corticosteroid administration, indicative of involvement of nongenomic glucocorticoid receptors (GR), and was associated with an increase in arterial blood pressure (17-21). The latter is a known effect of corticosteroids and is assumed to result from increased peripheral vascular resistance $(22,23)$. The decrease in FHR is generally believed to be caused by a vagally mediated baroreceptor response to increased systolic blood pressure (19-23). Corticosteroids may foster hypertension by augmenting vascular tone through potentiation of the action of various vasoconstrictor hormones, but the precise mechanism is far from understood (23). Corticosteroids may also influence FHR through binding to GR in brainstem nuclei (24). The finding that all observed changes in FHR parameters were only statistically significant in the older fetuses at 29-33 wGA is in line with the results from a recent study (25). These gestation-related observations suggest immature cardiovascular control mechanisms and/or nonfunctional GR in the fetal brain, heart, or vessels at younger age.

The increase in FHR variability can be explained, to a large extent, by the known inverse relationship between basal FHR and its variation (26), which was also found in previous studies on the effects of corticosteroids $(5,8)$. In normal pregnancy, about $50 \%$ of the variation in FHR variability is accounted for by changes in heart rate itself (26). Our results are in keeping with this finding, although the amount of explained variation was lower $(\sim 30 \%)$ in the present study. The increase in FHR variability may also have resulted from changes in peripheral vascular resistance mediated through raised levels of catecholamines, which feed back via the baroreceptor loop (20).

It is unclear why ACC were increased $0-12 \mathrm{~h}$ and $24-30 \mathrm{~h}$ after the first dose of betamethasone. The increase in ACC in the secondary phase of this study has also been reported by others $(7,10)$. Although there is a strong association between ACC and fetal body movements in near-term pregnancy, this relationship is poor before $32 \mathrm{wGA}$, i.e. the age at which most fetuses were monitored in the present study. In addition, no changes were found in limb movements and nuchal muscle activity after betamethasone infusion into the fetal sheep (19). So, whether or not the increases in ACC are due to increased fetal bodily activity awaits further direct ultrasound observation. The possibility exists that corticosteroids lower the threshold for ACC to occur.

The primary and secondary effects of betamethasone on FHR parameters were, apart from the change in ACC, not identical. The secondary effects included unaltered basal FHR between $24 \mathrm{~h}$ and $48 \mathrm{~h}$ and decreased FHR variability $42-48 \mathrm{~h}$ after the first dose of betamethasone. These observations in the secondary phase of the study corroborate previous results (5-10). At the end of our study period, we noticed the beginning of the well-known decreases in LTV and STV that have previously been demonstrated to last until d 4 after the start of betamethasone treatment $(5-10)$. 
There is presently no evidence that corticosteroids may deteriorate the fetal condition. In an extensive Doppler study of fetal and uteroplacental blood flow velocity waveforms, Cohlen et al. (27) found no changes in resistance to blood flow nor signs of fetal brain-sparing (indicative of hypoxemia) after maternal betamethasone administration. Moreover, neither in the main group of the present study nor in previous studies, was a corticosteroid-induced change found in the occurrence of FHR decelerations, which are also important markers of fetal hypoxemia (5-10). Remarkably, in pregnancies with absent umbilical artery end-diastolic flow, betamethasone treatment was recently shown to be transiently associated with improved fetoplacental blood flow (and presumably improved fetal oxygenation) (28), but this result awaits thorough evaluation in independent future studies. However, it has been shown in chronically instrumented fetal sheep that a single dose of $12 \mathrm{mg}$ dexamethasone administered to the ewe resulted in a $10-20 \%$ reduction in fetal arterial $\mathrm{Po}_{2}$ by $1 \mathrm{~h}$ after the injection (20). This reduction remained present for the next $24 \mathrm{~h}$. Although hypoxic levels were never reached in these healthy sheep fetuses, this observation, as pointed out by the authors, raises questions as to the possible hazard of corticosteroid therapy in the compromised human fetus (20). During betamethasone therapy, we found fetal deterioration, as indicated by a rapid increase in FHR decelerations, to occur in 4 out of 11 compromised fetuses, and we did not refrain from intervention. If, or to what extent, betamethasone treatment was causally related to the fetal deterioration cannot be concluded from this study and further research is warranted. However, corticosteroids may augment hypoxemia in the compromised (IUGR) fetus who can otherwise still cope with its intrauterine needs under marginally hypoxic conditions. In contrast, the fetus showing transient changes in the other FHR parameters is not likely to be jeopardized in a mother receiving corticosteroids for threatened preterm delivery.

Acknowledgments. The authors thank G. Kortes-van Hoffen and M. Pomp for their valuable contributions to this study.

\section{REFERENCES}

1. NIH Consensus Development Conference 1995 Effects of corticosteroids for fetal maturation on perinatal outcomes. JAMA 273:413-418

2. Crowley P 2003 Prophylactic corticosteroids for preterm birth. Cochrane Database Syst Rev CD000065

3. Bos AF, van Asperen RM, van Eykern LA, Zijlstra WG, Okken A 1994 Heart rate, heart rate variability and metabolic rate in preterm infants with bronchopulmonary dysplasia in the first week of dexamethasone treatment. J Physiol 479:P23-P24

4. Kavelaars A, van der Pompe G, Bakker JM, van Hasselt PM, Cats B, Visser GH, Heijnen CJ 1999 Altered immune function in human newborns after prenatal admin- istration of betamethasone: enhanced natural killer cell activity and decreased T cell proliferation in cord blood. Pediatr Res 45:306-312

5. Mulder EJ, Derks JB, Visser GH 1997 Antenatal corticosteroid therapy and fetal behaviour. a randomized study of the effects of betamethasone and dexamethasone. Br J Obstet Gynaecol 104:1239-1247

6. Magee LA, Dawes GS, Moulden M, Redman CW 1997 A randomised controlled comparison of betamethasone and dexamethasone: effects on the antenatal fetal heart rate. Br J Obstet Gynaecol 104:1233-1238

7. Senat MV, Minoui S, Multon O, Fernandez H, Frydman R, Ville Y 1998 Effect of dexamethasone and betamethasone on fetal heart rate variability in preterm labour: a randomised study. Br J Obstet Gynaecol 105:749-755

8. Derks JB, Mulder EJ, Visser GH 1995 The effects of maternal betamethasone administration on the fetus. Br J Obstet Gynaecol 102:40-46

9. Kelly MK, Schneider EP, Petrikovsky BM, Lesser ML 2000 Effect of antenatal steroid administration on the fetal biophysical profile. J Clin Ultrasound 28:224-226

10. Subtil D, Tiberghien P, Devos P, Therby D, Leclerc G, Vaast P, Puech F 2003 Immediate and delayed effects of antenatal corticosteroids on fetal heart rate: a randomized trial that compares betamethasone acetate and phosphate, betamethasone phosphate, and dexamethasone. Am J Obstet Gynecol 188:524-531

11. Ballard PL, Ballard RA 1995 Scientific basis and therapeutic regimens for use of antenatal glucocorticoids. Am J Obstet Gynecol 173:254-262

12. Davey DA, MacGillivray I 1988 The classification and definition of the hypertensive disorders of pregnancy. Am J Obstet Gynecol 158:892-898

13. Wide-Swensson D, Montan S, Arulkumaran S, Ingemarsson I, Ratnam SS 1993 Effect of methyldopa and isradipine on fetal heart rate pattern assessed with computerized cardiotocography in human pregnancy. Am J Obstet Gynecol 169:1581-1585

14. Kloosterman GJ 1970 On intrauterine growth, the significance of prenatal care. Int J Gyn Obstet 8:895-912

15. Arduini D, Rizzo G 1990 Normal values of Pulsatility Index from fetal vessels: a cross-sectional study on 1556 healthy fetuses. J Perinat Med 18:165-172

16. Dawes GS, Moulden M, Redman CW 1991 System 8000: computerized antenatal FHR analysis. J Perinat Med 19:47-51

17. Kari MA, Hallman M, Eronen M, Teramo K, Virtanen M, Koivisto M, Ikonen RS 1994 Prenatal dexamethasone treatment in conjunction with rescue therapy of human surfactant: a randomized placebo-controlled multicenter study. Pediatrics 93:730-736

18. Moïse AA, Wearden ME, Kozinetz CA, Gest AL, Welty SE, Hansen TN 1995 Antenatal steroids are associated with less need for blood pressure support in extremely premature infants. Pediatrics 95:845-850

19. Derks JB, Giussani DA, Jenkins SL, Wentworth RA, Visser GH, Padbury JF, Nathanielsz PW 1997 A comparative study of cardiovascular, endocrine, and behavioural effects of betamethasone and dexamethasone administration to fetal sheep. J Physiol 499:217-226

20. Bennet L, Kozuma S, McGarrigle HH, Hanson MA 1999 Temporal changes in fetal cardiovascular, behavioural, metabolic and endocrine responses to maternally administered dexamethasone in the late gestation fetal sheep. $\mathrm{Br} \mathrm{J}$ Obstet Gynaecol 106:331-339

21. Koenen SV, Mecenas CA, Smith GS, Jenkins S, Nathanielsz PW 2002 Effects of maternal betamethasone administration on fetal and maternal blood pressure and heart rate in the baboon at 0.7 of gestation. Am J Obstet Gynecol 186:812-817

22. Whitworth JA, Brown MA, Kelly JJ, Williamson PM 1995 Mechanisms of cortisolinduced hypertension in humans. Steroids 60:76-80

23. Ullian ME 1999 The role of corticosteroids in the regulation of vascular tone. Cardiovasc Res 41:55-64

24. de Kloet ER, Reul JM, Sutanto W 1990 Corticosteroids and the brain. J Steroid Biochem Mol Biol 37:387-394

25. Mulder EJ, Koenen SV, Blom I, Visser GH 2004 The effects of antenatal betamethasone administration on fetal heart rate and behaviour depend on gestational age. Early Hum Dev 76:65-77

26. Nijhuis IJ, ten Hof J, Mulder EJ, Nijhuis JG, Narayan H, Taylor D, Westers P, Visser GH 1998 Numerical fetal heart rate analysis: nomograms, minimal duration of recording and intrafetal consistency. Prenat Neonat Med 3:314-322

27. Cohlen BJ, Stigter RH, Derks JB, Mulder EJ, Visser GH 1996 Absence of significant haemodynamic changes in the fetus following maternal betamethasone administration. Ultrasound Obstet Gynaecol 8:252-255

28. Wallace EM, Baker LS 1999 Effect of antenatal betamethasone administration on placental vascular resistance. Lancet 353:1404-1407 